times getting well, and then becoming worse; a common history of joint-disease. When he applied for advice here, he was strumouslooking and thin. There was no swelling over the patella, but rather a depression. There was a large swelling, containing fluid, extending up the thigh from the inside of the knee, and it was doubtful whether it communicated with the joint. For some time I was also rather doubtful whether the fluid were serum or pus, and I determined to satisfy myself by a careful puncture with a narrow-blader knife dipped in carbolised oil. I found evidence of the presence of flaky, curdy pus, and opened it freely. The abscess went close to the condyles of the femur, and I felt bare bone. There was here tubercular synovitis, which probably originated, or was associated with, exposure of the bone. The bone was not diseased all through, but it had become diseased at the synovial margin. The joint was becoming disorganised.

I first attempted palliative treatment, making a free incision outside of the patella, and there is no doubt that this passed right into the joint. You saw the relief of the symptoms in consequence of these and other incisions. It is quite a mistake to think that an incision into a diseased joint is like admitting the air into a joint that is healthy. In the one case, the patient's symptoms will all improve; in the other, acute inflammation will set in. Mr. Gay proposed it as a means of treating joint-disease generally : he recommends opening the joint freely and putting on splints.

You may get occasional cures by doing little or nothing; but in these the treatment may last over five or six years or more. Some say that you will generally get a cure if you wait long enough; but this "long enough" implies the danger of tubercle in other parts of the body, exhaustion, and ultimately death. Excision is an alternative, and there may arise the question of amputation; but, considering that, perhaps, one case in four or five of amputation of the thigh dies, and that the mortality of excisions is scarcely, if at all, greater, excision maintains, usually, the decided advantage of preserving a limb instead of a stump. I am trying to improve this patient's health, if possible, to enable him to sustain an operation, either excision or amputation. It is a mistake to attempt to interfere during an exacerbation of the disease. If you can wait till the symptoms are quieter, and do the operation then, you will have a much better chance of success.

Lastly, I have to call your attention to another case of joint-disease - gelatinous degeneration of the wrist-joint. I excised the wrist the other day. There we had a swollen, pulpy, elastic mass, not accommodating itself to the shape impressed by the tendons, as a fluid effusion does, but pushing aside the natural structures; in consequence of this, the joint assumes a rounder outline than in fluid effusion. This gelatiniform tendency in the synovial membrane affects the sheaths of the tendons in the same way, and you hardly ever find the disease confined to the joint alone. This contributes to produce a rounded swelling, which, in the earlier stage, is attended with hardly any pain. Why is there no pain? Because the elastic deposit separates the surfaces of the joint, invades, softens, and breaks down the fibrous, cartilaginous, and ligamentous structures, and prevents pressure on the nerves of the joint. But pain comes when abscesses form in the softened tissues. They may form all round the joint, and yet not communicate with it. Sir Benjamin Brodie was the first to call attention to this form of disease. It is more intractable than any other. In five cases in which I have performed excision, there have been in three the satisfactory result of a tolerably useful, and in one case, movable wrist. In another, however, sinuses still remain, and symptoms of pulmonary tubercle have made their appearance.

\section{A NEW METHOD OF TREATING HYDROCELE.*}

\section{By S. MESSENGER BRADLEY, F.R.C.S., Manchester.}

WHILE the various plans of treating hydrocele hitherto recorded possess the prestige of a high antiquity, they all alike suffer from being occasionally unsuccessfu!, or even hurtful, in their results. These objections hold good, though in a less degree, in speaking of the treatment by tapping and injecting the vaginal sac, which has practically superseded all other modes. This operation, first recommended by Celsus, who advised nitre as the best injection, fell into a long desuetude after his death, until revived by Monro the elder, and of late years popularised by Sir Ranald Martin, whose claim to originality lies in his choice of iodine as the most suitable stimulating agent. Other plans are, however, resorted to from time to time, either from their greater safety and simplicity, or from the occasional failure of the iodine treatment. Thus, briefly to summarise these methods, we have-1, treatment by acupuncture, recommended by Lewis, and still sometimes adopted and found to succeed in cases of congenital hydrocele; 2 , the mere application of an evaporating lotion, such as muriate of ammonia, vinegar and water, which, it is probable, has only been found of service by Keate, who, I believe, was the first to recommend it to the profession; 3, simple tapping, nearly always failing to effect a cure, and not always without danger, inasmuch as it is sometimes followed by a hæmatocele, or even sloughing of the scrotum; 4, layin open the sac, a plan approved by the fathers of medicine, but abandoned by their descendants of the present day; 5, excision of a portion of the tunica iaginalis, which has, in having been practised by Albucasis, an almost equal antiquity with the one last mentioned, and has met with quite an equal neglect; 6, the plan of evacuating the fluid and introducing some caustic on the end of a probe, of which Paulus Agineta writes in warm praise, and which, though occasionally adopted, as Humphry states, at the present day, is not likely either from its success or safety to become more general than it deserves; 7 , the introduction of a tint into an opin wound, as performed and praised by Paré, Baron Larrey, and others ; and 8 , the somewhat similar plan, still, I believe, commonly practised by the Arabians, who were the first to adopt it, of passing a seton through the vaginal sac, and there retaining it for twenty-four hours. It is likely enough that this operation would succeed in cases which resist all milder treatment, but, from the by no means trifling danger attending it, it should not be resorted to if we can equally achieve our object by a safer mode of procedure ; and this, I believe, can be done, as I will endeavour to show.

It very frequently happens that a hydrocele must be treated, if treated at all, in the out-patient department of a hospital or at the surgeon's residence ; that is to say, at a distance from the patient's own home. Now the disadvantages arising from this fact are, that the walk home after operation is apt to induce considerable and even dangerous inflammation, or that a hæmatocele ensues as the result, not necessarily of wounding the testicle, but of a dribbling from the scrotal veins, which are turgid from their dependent position.

Pondering these circumstances, and also reflecting upon the fact that the walls of pyogenic membranes, such as those of abscesses, sinuses, and the like, will often agglutinate when brought into firm and contined apposition; and remembering, at the same time, that the serous tunic of the testicle is from its physiological nature liable to take on adhesive action, and that, from the character of the secretion poured out in a hydrocele being inflammatory and not dropsical, it would even be prone to do so, I was led to the inference that simple tapping, followed by firm and equal strapping of the affected side, would probably be folluwed by an obliteration of the vaginal sac and a consequent radical cure.

It was not long before I was enabled to test the accuracy of this reasoning. A medical man applied to me with a large simple hydrocele, which had been tapped several times, and the last time injected with iodine without success. After explaining my object to him, I tapped the hydrocele, drawing off half a pint of fluid, and tightly strapped the affected testicle with soap-plaster. This was done at my own house, and the patient walked home, a distance of about a mile, immediately afterwards, and continued to go about during the process of recovery, which probably took place in about ten days; I say probably, as I kept up the pressure for three weeks without allowing the testicle at any time to remain unsupported. This case occurred eight months ago; since then I have followed the same course in three other instances, and in each with an equally satisfactory result. In no case was there any fresh effusion of fluid. Another case which came under - my notice was of some interest in illustrating the advantages of strapping in what would beforehand appear quite unfavourable circumstances. A man came to consult me about a recent hydrocele of some magnitude; I tapped and emptied the tumour, but did not strap it at the time, as there was a strong force of pediculi encamped in the pubic and scrotal hair; ten days afterwards, he visited me again, having got rid of his unwelcome guests, but with his tunica vaginalis as much distended as ever. I again tapped him; but, though I do not think I wounded the testicle, which could be plainly enough seen at the back of the tumour, I did not succeed in drawing off any fluid worth speaking of; nothing followed, indeed, but a few drops of bloody serum. In three days he came again with his scrotum larger than ever. The tumour had now, however, changed its character; it was no longer transparent and pear-shaped, but opaque and rounded; it had also become very heavy and much more painful than it had ever been before. In other words, a hæmatocele had formed. Without the anticipation of much good resulting, I resolved to try the effect of strapping in this case; suffice it to say that this proved effectual, not only in causing the absorption and dispersion of the vascular extravasation, but also in permanently curing the hydro- 
cele. In spite, however, of the success in this instance, I am not inclined to think that the plan would prove generally efficacious in the treatment of even recent hæmatocele, and I do not now at all desire to advocate it in such cases.

In regard, however, to hydrocele, it appears to me that we have in this plan of tapping and strapping one which satisfactorily fulfils the idea of curing safely, quickly, and pleasantly, and which, though perhaps not about to prove infallible, is one which should be certainly tried in all cases (especially, I would add, those treated away from the patient's home), before the injection of iodine or other stimulant is resorled to. If cases occur in which neither the mode I here advocate nor the iodine treatment is successful, I am of opinion that a combination of the two would be likely to prove so.

\section{CHLOROFOR M DEATHS.}

By W. F. MORGAN, F.R.C.S., Consulting Surgeon to the Bristol Royal Infirmary.

I BEG to add my testimony to the truth and importance of the statements contained in the valuable paper on chloroform contributed to the last number of the JOURNaL by my friend and colleague Mr. Green. I fully believe with him that failure of the heart is the great source of danger in its administration ; and that electricity, cautiously employed, is the most prompt and certain remedial measure. I shall not soon forget a striking example in the case of an old man admitted with strangulated hernia. The taxis under ordinary circumstances having failed, he was put under chloroform for another trial previously to operation. The hernia was now readily reduced, but immediately he became deadly pale, his pulse stopped, and he seemed in articulo mortis. Instant recourse was had to the electro-magnetic battery, and almost as instantly the pulse returned, and the man was safe.

In my experience, whenever dangerous symptoms have arisen, the heart has been the organ affected; and that is, I believe, the result to be watched and provided for when chloroform is administered. I can readily imagine that the lungs may suffer and asphyxia be produced by complicated apparatus and failing valves, mechanically suffocating the patient. Nothing can be more simple, and in my judgment more safe and effectual, than the plan adopted at the Bristol Royal Infirmary. A hollow sponge, conical in shape, with a hole at the apex, is held loosely over the mouth and nostrils, the chloroform being sprinkled on the interior, with or without the intervention of a bit of lint, the ad. mission of air being regulated by a thumb on the hole at the apex. In the two deaths from chloroform which have occurred in the Infirmary, only a very moderate quantity was used, as if the unfortunate result were due to some idiosyncracy.

My chief object, however, in supplementing Mr. Green's paper, is to give a word of caution in the use of electricity in cases of threatened death from syncope. It is well known that a powerful electric shock sent through the par vagum will paralyse the heart and stop its action. Hence, if we be not careful, we may inadvertently increase the evil which we are endeavouring to remedy.

\section{HEALING OF WOUNDS AND ULCERS BY A NEW METHOD.}

By JAMES BRAITHWAITE, M.D., Leeds, Editor of Braithwaiti's Annual Retrospect of Medicine and Surgery.

THE application of an aqueous solution of carbolic acid (one drachm to eight ounces of water) to an ill-conditioned ulcer, cleans it from al purulent matter, and causes it to assume a healthy red appearance, with each granulation distinctly visible. If a wound in this state be freely exposed to warm dry air for some hours, it becomes glazed and dried on the surface. It becomes covered by what is practically an impervious transparent membrane, closely applied to the surface of the granulations, and exercising a certain amount of mechanical pressure upon them. In many cases, no matter forms underneath this membrane, and cicatrisation goes on underneath it with great rapidity. In time, the membrane assumes the appearance of a thin dry scab, and drops off. If matter form under the membrane, it is at once visible through it; the lotion should then be reapplied, and the wound dried by exposure, as before. Immediately this is done, the inflamed edges of the ulcer commence to pale in colour, and in twenty-four to thirtyfour hours have nearly the tint of natural skin.

This treatment is especially of value in the cure of ulcers on the leg, as no confinement to bed is necessary; and what is required in the application of the lotion and subsequent drying can be done in the evening, after the conclusion of the day's work.

The first case in which I tried this plan was that of Godfrey S. $\mathrm{He}$ had been thrown off his ordinary business twice, for a period of four to six weeks, with an ulcer on the shin of the right leg. It healed the first time; but on the second occasion it resisted all treatnent, although he laid in bed two weeks. I then tried the plan recommended, and he returned to work in a week. Of course, the wound was unhealed, but it was covered with a firm scale. This dropped off many weeks afterwards, leaving a healthy cicatrised surface.

Another case was that of John M., a hairdresser, accustomed to be on his feet all day. The lower half of his left leg anteriorly was one mass of inflammation and deep ulcers, secreting unhealthy pus, and with irregular edges. This was cured by this plan alone, thanks to his own intelligence and care, without his being one day off his work.

I have tried this plan in numerous cases of small wounds, but do not think it applicable for sores of large size-say six or seven inches across-from a scald. I have met with one case which defied this plan of treatment. It was a chilblain on the foot of a very strumous child, just returned from India. She had at the same time pemphigus on the backs of both hands. The profuse suppuration was too much for the mechanical pressure of the membrane to check it ; and although cleaned, dried, and glazed repeatedly, pus always formed underneath. I at last simply dressed it with spermaceti ointment, and it healed by contraction in about two months. Of course, the membrane or scab acts not merely by pressure, but by exclusion of the air.

\section{OBSTETRIC MEMORANDA.}

\section{STATISTICS OF OVARIOTOMY.}

I SEND, as it were, a drop in the ocean. I have only had one case of ovariotomy, which did well for three days, when a low form of peritonitis set in and killed on the tenth day. If particulars of every case of ovariotomy, successful and unsuccessful, could be col. lected, the statistics would be interesting.

Miss - - a farmer's daughter, aged 36 , a private patient, was operated upon at lodgings in Stamford. Chloroform was not given. The æther spray was used to the skin of the abdomen. An unilocular cyst was removed from the left ovary ; it contained two gallons of thick glairy fluid. She had not been tapped. No fluid escaped into the peritoneum. The pedicle was three inches long. Hutchinson's clamp was applied. She died on the tenth day after the operation, from asthenic peritonitis. J. M. HAWARD, Stamford.

The following represents the whole of my experience. All the cases occurred in private practice.

I. Aged 26, married; died of peritonitis. 2. Aged 23, single ; recovered. 3. Aged 24, married; recovered. 4. Aged 35, married; recovered. 5. Aged 45, married; recovered; 6. Aged 35, married; re. covered. 7. Aged 47, widow ; recovered. 8. Aged 42, widow; recovered. 9. Aged, 32, married; recovered.

\section{LAwSON TAIT, F.R.C.S., Birmingham.}

I. Elizabeth W., aged I8, single, had ovariotomy performed June I 7 th, I 869. The cyst was unilocular; the pedicle was clamped. She was discharged cured August rst, I 869 .

2. Mary B., aged 35, married, the mother of five children (the youngest three years old), had an ovarian cyst with a solid portion, and ascites in small quantity. She was admitted February 23rd, 1870. On March I 7 th, ovariotomy was performed. The pedicle was clamped. The cyst consisted of one large and a few mural cysts, and at the lower part a large intracystic growth of a colloid character. She was discharged cured May I 7 th, I 870.

3. Mrs. B., aged 35, mother of two children, was admitted March 22nd, 1870. She was an anxious and careworn woman, and was suspected of drinking slightly. Her family history was indifferent. Her mother died of uterine cancer in the Samaritan Hospital, London. She had a multilocular medium-sized ovarian cyst of six years' duration. Extensive adhesions were suspected. In April, ovariotomy was performed. There were adhesions to a coil or two of small intestine and omentum, and to the fundus uteri ; they were separated before the cyst was removed. The pedicle was short; it was ligatured (the ends being retained outside the wound). The operation was prolonged. Death took place forty-eight hours after the operation, from shock. There was no internal hæmorrhage, as was ascertained by post mortem examination. 4. Eliza P., aged 42, unmarried, was admitted November 22nd, 